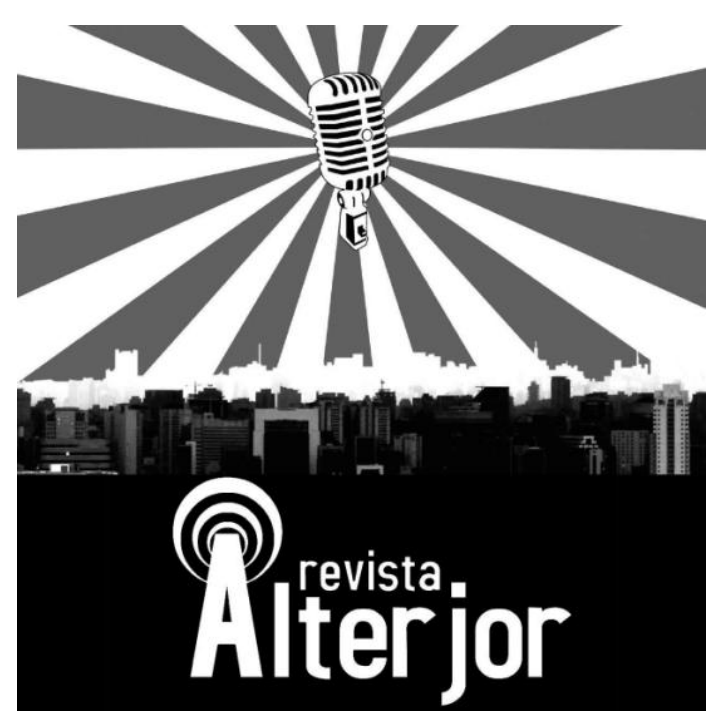

DOSSIê: "Comunicação nas Periferias"

\title{
UM RELATO DE EXPERIÊNCIA DO PROJETO ELAS SOBREOTATAME: IMPACTOS DE UM CIBERATIVISMO FEMINISTA
}

\author{
Ingrid Pereira de Assis ${ }^{1}$ \\ Juliana Gobbi Betti \\ Larissa Silva Abreu ${ }^{3}$ \\ Joceline Conrado da Silva ${ }^{4}$
}

RESUMO: O Elas SobreOTatame é um projeto desenvolvido sob coordenação das mulheres do portal maranhense SobreOTatame (SOT), que trabalha temas a partir de um olhar feminista, produzindo conteúdos jornalísticos e eventos em ciclos temáticos, com a participação de profissionais especialistas no tema debatido. Este relato de experiência foi produzido a partir dos resultados de uma pesquisa realizada com as participantes dos eventos ocorridos em 2019, cujo objetivo foi compreender os impactos do projeto na vida dessas mulheres. Foi aplicada uma entrevista semiestruturada, tendo como direcionamento a compreensão da emancipação, autonomia e formação de conhecimento acerca das temáticas abordadas. Este relato de experiência traz os resultados apreendidos nesta pesquisa, visando contribuir para a formação e desenvolvimento de iniciativas comunicacionais de fortalecimento da mulher frente a uma sociedade desigual.

PALAVRAS-CHAVE: Feminismo. Elas SobreOTatame. Ativismo feminista. Jornalismo.

\footnotetext{
${ }^{1}$ Doutora em Jornalismo, pela Universidade Federal de Santa Catarina (UFSC), com doutorado sanduíche pela Universidade de Aveiro (Portugal); mestra em Ciências Sociais, pela Universidade Federal do Maranhão (UFMA); e bacharel em Comunicação Social - Hab. Jornalismo, também pela UFMA. E-mail: ingrid.p.assis@ hotmail.com

${ }^{2}$ Bolsista Capes DS. Doutoranda e mestra em Jornalismo pela Universidade Federal de Santa Catarina (UFSC); graduada em Comunicação Social - habilitação em Jornalismo, pela Universidade Metodista de São Paulo. E-mail: jugobbibetti@gmail.com

3 Redatora do SOT. Professora do Instituto Estadual de Educação, Ciência e Tecnologia do Maranhão (IEMA); mestranda do Programa de Pós-Graduação em Psicologia, da Universidade Federal do Maranhão (UFMA); especialista e licenciada em Filosofia pela UFMA; e bacharel em Psicologia, também pela UFMA. E-mail: larisssa.abreu@gmail.com

${ }^{4}$ Redatora do SOT. Pós-graduanda em Políticas Públicas e Desenvolvimento Social pela Pontifícia Universidade Católica do Paraná (PUC-PR) e em Teoria Psicanalítica pela Faculdade Laboro (MA), e graduada em Psicologia pela Universidade Ceuma (MA). E-mail: jocelinecs@gmail.com
}

\section{Revista ALTERJOR}

Grupo de Estudos Alterjor: Jornalismo Popular e Alternativo (ECA-USP)

Ano 10 Volume ol Edição 23 Janeiro-Julho de 2021

Avenida Professor Lúcio Martins Rodrig̉ues, 443, Cidade Universitária, São Paulo, CEP: 05508-020 


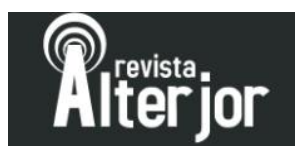

ABSTRACT: Elas SobreOTatame is a project developed under the coordination of women in the portal SobreOTatame (SOT), from Maranhão, which works themes from a feminist point of view, producing journalistic content and events in thematic cycles, with the participation of professionals specialized in the topic discussed. This experience report was produced based on the results of a survey conducted with the participants of events that took place in 2019, whose objective was to understand the impacts of the project on the lives of these women. A semi-structured interview was applied, aiming at understanding emancipation, autonomy and knowledge formation about the topics covered. This experience report brings the results learned in this research, aiming to contribute to the formation and development of communication initiatives to strengthen women in an unequal society.

KEYWORDS: Feminism. Elas SobreOTatame. Feminist ativism. Journalism.

\section{INTRODUÇÃO}

O Elas SobreOTatame é um projeto de midiativismo feminista, produzido pelo portal jornalístico maranhense SobreOTatame $(S O T)^{5}$. Este veículo tem como tripé temático cidadania, cultura e comportamento. O objetivo principal do portal é utilizar as diferentes ferramentas possibilitadas pelas plataformas digitais ${ }^{6}$ para trabalhar temas de relevância social, abrindo espaço midiático para as narrativas populares e para o fortalecimento do cenário artístico independente, principalmente, as expressões estéticas locais e regionais de áreas periféricas do Maranhão. O SOT começou no ano de 2014 e, atualmente, possui uma equipe fixa de 17 profissionais das mais diversas formações, entre elas: Comunicação Social, Psicologia, Letras e Direito. Os conteúdos produzidos prezam pela multimidialidade e exploram as possibilidades de diferentes plataformas (ASSIS; BETTI; SAMPAIO, 2019). Nos últimos anos, o portal passou a apostar em projetos que extrapolassem o ambiente digital, desenvolvendo versões físicas e ampliando, assim, os canais de diálogo e construção de conhecimento com seu público.

\footnotetext{
${ }^{5}$ O SobreOTatame está presente em diferentes ambientes e seus conteúdos podem ser acessados no site (www.sobreotatame.com) e, também, nos perfis criados nas plataformas de redes sociais: YouTube, youtube.com/channel/UC89PP6DqRTMXVf5Hw0nlLrg; Facebook, facebook.com/SobreOTatame/; Twitter, twitter.com/sobreotatame; e Instagram, instagram.com/sobreotatame/.
} 


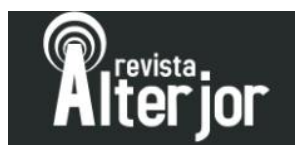

Um dos projetos criados neste formato é o Elas SobreOTatame, que é o foco deste artigo.

O Elas SobreOTatame, como o próprio nome antecipa, é um projeto de midiativismo voltado à temas que façam parte do dia a dia das mulheres. Além da produção jornalística multimídia de conteúdos informativos e opinativos acerca da temática escolhida, a iniciativa extrapola o ambiente digital, realizando ações físicas em ciclos de três meses. Ao longo dos meses, são produzidos textos, vídeos e podcasts com a proposta do ciclo e, ao final, ocorre um encontro presencial, com a participação de convidados especiais cujas atuações estejam diretamente relacionadas às áreas do tema debatido.

O projeto se insere num palco de novas formas comunicacionais que buscam, por meio do ambiente das plataformas de redes sociais e do próprio portal, amplificar vozes menos escutadas nos jogos dominantes das relações de poder. Assim, o cenário de ativismo feminino regional adentra a ambiência do ciberespaço, compactuando com as tendências atuais no protagonismo do movimento feminista, pois conforme já identificado por Ureta (2005, p. 381):

...o feminismo é chamado a se estabelecer em novos espaços comunicativos, longe do império tradicional da mídia de massa. Para isso, o ciberespaço apresenta-se como uma alternativa mais do que plausível, favorecendo a criação de modelos de divulgação menos dependentes dos canais tradicionais. Além disso, o espaço virtual da Internet disponibiliza ao movimento feminista poderes expressivos desconhecidos, entre outros, um novo sentido da comunicação coletiva que transforma as mulheres em autoras, transmissoras e receptoras de informação.

No ano de 2019, o SOT realizou três edições do projeto que discutiram, respectivamente: autoconhecimento e prazer feminino, maternidades; e saúde mental das mulheres. O objetivo deste artigo é compreender as apreensões das participantes que compareceram às rodas de conversa e os possíveis impactos do projeto em suas vivências. Buscou-se entender em que medida a participação nessas rodas contribuiu 


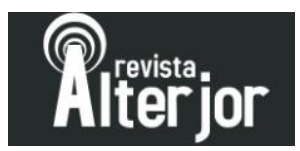

para os processos individuais de emancipação, autonomia e formação de conhecimento acerca das temáticas abordadas.

Para isso, foi realizada uma pesquisa de opinião, a partir de entrevistas semiestruturadas, aplicada via formulário virtual com as mulheres participantes dessas três edições do projeto. $\mathrm{O}$ artigo traz, então, a análise dos resultados dessa pesquisa de opinião articulada com um breve relato da experiência de desenvolvimento do projeto. Ao fim, espera-se contribuir para a uma melhor compreensão acerca do Elas SobreOTatame, colaborar para a seu aprimoramento, bem como cooperar para a formação e desenvolvimento de iniciativas jornalísticas que combatam o silenciamento de informações vitais para o fortalecimento das mulheres, sobretudo mulheres de áreas periféricas, frente a uma sociedade comprovadamente tão desigual ${ }^{7}$.

\section{DESCRIÇÃO DO PROJETO}

A primeira edição do projeto Elas SobreOTatame foi realizada entre os meses de janeiro e março de 2019. O tema trabalhado neste ciclo foi "Prazer Feminino e Autoconhecimento". Dentre os textos produzidos neste período estão: "O que te faz gozar, mulher?", "Você já é uma mocinha" e "Tornando-se mulher com outras mulheres". Em formato podcast, esta primeira edição trouxe o "Do luxo ao Lixo: experiências em apps de paquera" e uma entrevista com Seane Melo, jornalista e escritora de livros eróticos. A produção audiovisual focou na cobertura do encontro, que foi realizado no formato de "roda de conversa". Figueirêdo e Queiroz (2013) defendem que a metodologia de roda de conversa possibilita a construção do pensar compartilhado, à medida que cada participante elabora suas questões acerca da temática proposta, existe um processo de significação coletiva de cada fala, gerando

\footnotetext{
${ }^{7}$ No ano de 2019, segundo o Fórum Econômico Mundial, o Brasil ocupava a $92^{\text {a }}$ posição no ranking que mede a igualdade entre homens e mulheres, em um total de 153 países. Isso porque as mulheres brasileiras estão sub-representadas na política, têm remuneração menor, além de serem mais vulneráveis ao desemprego e, ainda, sofrerem assédio. De acordo com a Organização Mundial da Saúde (OMS), o Brasil é o quinto país do mundo em número de feminicídios, por exemplo. Todos esses aspectos apontam para a desigualdade entre homens e mulheres no país.
}

Revista ALTERJOR

Grupo de Estudos Alterjor:Jornalismo Popular e Alternativo (ECA-USP)

Ano 10 Volume Ol Edição $23 \quad$ Janeiro-Junho de 202l

Avenida Professor Lúcio Martins Rodrig̉ues, 443, Cidade Universitária, São Paulo, CEP: 05508-020 


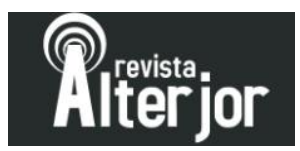

fortalecimento do grupo. Os diálogos e as dúvidas das participantes foram mediados pela psicóloga Raquel Cantanhede e pela fisioterapeuta pélvica Juliana Torres.

O tema da segunda edição foi "Maternidade". Nela, foram produzidos quatro textos: "Nós e nossas mães: uma reflexão sobre a relação entre mãe e filhas”, “Às mães solo, com amor e empatia", "Violência obstétrica: a maternidade não deve começar assim!" e "Puerpério: seis relatos de experiências sobre a desromantização do pósparto". Após a publicação do último texto, foi realizada a segunda roda de conversa entre mães e não-mães. O objetivo era que fosse criado um espaço no qual elas pudessem falar e ouvir sobre as alegrias, dores e, também, tirar dúvidas sobre maternidades. Neste segundo encontro ocorreu, ainda, uma oficina de biodança, para finalizar as atividades com um momento de integração relaxante e divertido. Este ciclo do Elas SobreOTatame contou com a presença da enfermeira e doula Danni Lima, além da psicóloga Laura Rosa, mediando as discussões e elucidando dúvidas das participantes.

Figura 1 - Registro da roda de conversa do II Encontro Elas SobreOTatame

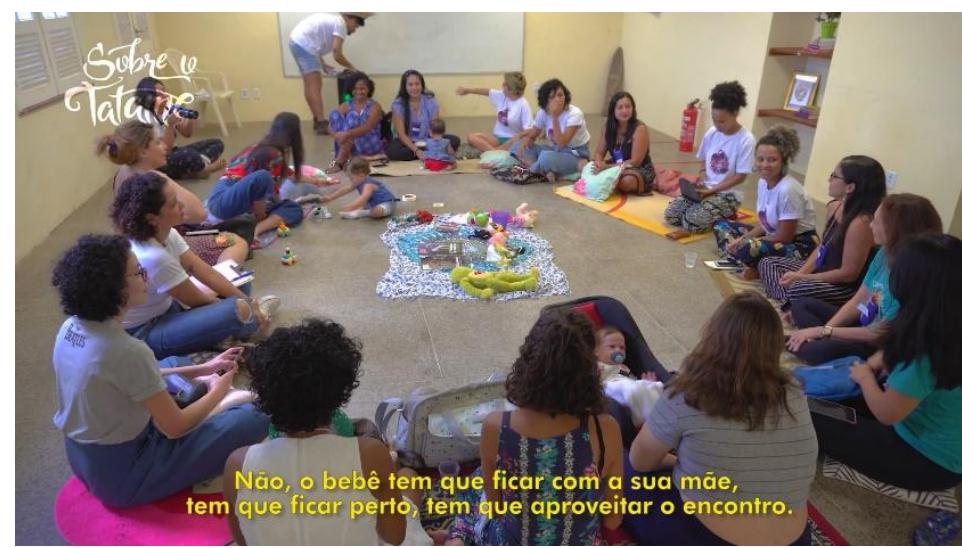

Fonte: Imagem retirada do vídeo produzido pelo SOT

O terceiro momento do Elas SobreOTatame, no ano de 2019, teve como tema “Te cuida Mulher!”, voltado à saúde mental das mulheres, alinhando-se à campanha do Setembro Amarelo, cujo foco é a prevenção do suicídio. Com o propósito de informar, conscientizar e incentivar reflexões, foram produzidos os textos "Saúde mental da mulher: por que a gente quer falar disso?”, “Ansiedade, Depressão e Redes Sociais: por

\footnotetext{
Revista AL TERJOR

Grupo de Estudos Alterjor:Jornalismo Popular e Alternativo (ECA-USP)

Ano 10 Volume ol Edição $23 \quad$ Janeiro-Junho de 2021

Avenida Professor Lúcio Martins Rodriģues, 443, Cidade Universitária, São Paulo, CEP: 05508-020
} 


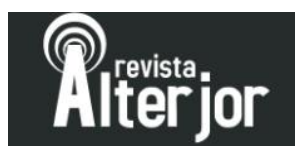

que mulheres sofrem mais com o fenômeno da hiperexposição?", "Sobre se conhecer e respeitar (ou doar boleto a pagar)", "Saiba como funciona a Rede de atendimento à Saúde Mental, em São Luís”, "Transtorno Afetivo Bipolar: o que precisamos saber para tratar nossos preconceitos", "Transtornos alimentares: quando não conversamos com nosso corpo", "Pra não dizer que não falei dos espinhos" e "Por que as mulheres estão adoecendo tanto?”. Essas produções trabalharam de forma integrada a temática da saúde mental e os desafios da atualidade, tais como o uso de redes sociais e os transtornos de imagem potencializados pela hiperexposição. O terceiro encontro foi mediado pela psiquiatra Maurilene Barcelar e pela psicóloga Bartira Oliveira.

\section{MIDIATIVISMO FEMINISTA NO MARANHÃO}

As mídias maranhenses, historicamente, organizam-se em conglomerados de comunicação controlados por famílias detentoras de poderes políticos e econômicos no Estado $^{8}$. Uma prática antidemocrática pela qual "se reforçam os vínculos históricos que sempre existiram entre as emissoras de rádio e televisão e as oligarquias políticas locais e regionais" (LIMA, 2008, p. 27). Desenha-se, assim, um contexto no qual prevalece um jornalismo excludente, que expropria de alguns cidadãos o direito de ser visto e ouvido, ou seja, de existir socialmente (PINTO, 2009).

Uma via alternativa vem crescendo nos últimos anos no Estado com o desenvolvimento de mídias contra-hegemônicas, que abrem espaços de visibilidade para ações, pessoas ou eventos que não conseguiriam abertura das mídias tradicionais. $\mathrm{O}$ SOT é um exemplo disto, visto que foi criado com o objetivo inicial de ser um espaço

8 Os dois principais conglomerados de comunicação são a Rede Mirante de Comunicação, majoritariamente pertencente à família Sarney, e o Sistema Difusora de Comunicação, hoje arrendado pelo deputado federal Weverton Rocha, mas pertencente à família Lobão. Ambos concentram canais televisivos, rádios e portais. A Rede Mirante possui ainda o jornal O Estado do Maranhão. Outros jornais impressos são: O Imparcial, que integra os Diários Associados, e o Jornal Pequeno, pertencente à família Bogéa. Dentre os portais de notícias se destacam: Imirante.com, G1 Maranhão e o portal do Jornal O Estado do Maranhão, todos da Rede Mirante; portal MA10(antigo Idifusora), do Sistema Difusora; os portais dos periódicos O Imparcial e Jornal Pequeno; além dos portais referentes a outros canais de televisão, como Sua Cidade (da TV Cidade - Rede Record) ePortal Guará (da TV Guará - Record News).

Revista ALTERJOR

Grupo de Estudos Alterjor:Jornalismo Popular e Alternativo (ECA-USP)

Ano 10 Volume Ol Edição 23 Janeiro-Junho de 202l

Avenida Professor Lúcio Martins Rodrig̉ues, 443, Cidade Universitária, São Paulo, CEP: 05508-020 


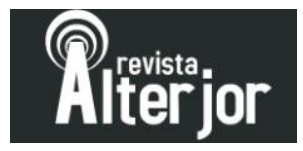

de diálogo e de visibilização de pessoas e iniciativas, que não conseguem espaço nas mídias tradicionais, incentivando a cidadania regional. Como demarca Barbero (2004), a cidadania perpassa o reconhecimento recíproco e está vinculada ao direito de informar e de ser informado, de falar e ser ouvido. "O cidadão é o indivíduo num lugar" (SANTOS, 2014, p. 151), sendo caracterizado, sobretudo, por ser ativo nas decisões coletivas.

Ao se posicionar neste sentido, o SOT pode ser classificado enquanto um midiativismo, que consiste em um fenômeno social que inclui o "ativismo mediático por meio de meios de comunicação, dentro deles e sobre eles" (PERUZZO, 2018, p. 58), podendo apresentar as mais diferentes feições. $\mathrm{O}$ ativismo se manifesta nas produções jornalísticas e culturais, que, conforme já destacado, é comprometida com a diversificação das fontes e pluralização do discurso que ocupa a esfera pública regional, objetivando subverter a hegemonia discursiva dos veículos de comunicação tradicionais do Estado. Isso porque, conforme ressalta Pasquali (2005), a comunicação é um direito humano indissociável, presente nas relações interpessoais e comunitárias, estando diretamente vinculada ao processo de preservação da cultura e exercício da cidadania. A comunicação também é fundamental para a "continuação do desenvolvimento da liberdade e da democracia" (FERREIRA, 2009, p. 195). Dessa forma, ao projetar falas usualmente eclipsadas pelos veículos tradicionais, o SOT amplia a gama de temas e vozes autorizadas por meio do jornalismo e assume, assim, uma perspectiva freireana, que sustenta a necessidade da responsabilidade ética ao se mover no mundo (FREIRE, 2011).

O midiativismo do portal se ampara na diversificação das narrativas e geração de um tipo de conhecimento marcado por um viés transformador do establishment, visando a construção de uma sociedade mais inclusiva e justa. Conforme apontam Nobert Elias e John L. Scotson (2000, p. 208):

As pessoas que constituem um establishment e bloqueiam o acesso de grupos outsiders a determinadas informações e decisões, podem ser, por seu lado, outsiders no que diz respeito a establishments de uma ordem superior. Em ambos os sentidos, aqueles que monopolizam o acesso à informação e decisões asseguram para si mesmos certas 
fontes de superioridade em termos de poder e status. A destreza necessária para a aquisição de saber é uma dessas fontes. Segundo uma tradição antiga, o saber, inclusive o saber de como adquiri-lo, é visto apenas em sua qualidade de meio de conhecimento. Normalmente se dá pouca atenção ao saber como meio de poder.

O ElasSobreOTatame nasce dentro deste ambiente de midiativismo, partindo de uma perspectiva feminista para trabalhar conteúdos jornalísticos e extrapolar a produção de conteúdos com ações presenciais. Esta perspectiva faz com que um dos objetivos do projeto seja levar para a esfera pública discussões na qual o feminino não seja desvalorizado, criando uma dimensão de resistência perante uma sociedade desigual e que desfavorece sobretudo as mulheres, nos mais diferentes espaços sociais (trabalho, estudo, relações afetivas, família etc). Como explicam Branca M. Alves e Jacqueline Pitanguy (1985, p. 55):

A política, o sistema jurídico, a religião, a vida intelectual e artística, são construções de uma cultura predominantemente masculina. $\mathrm{O}$ movimento feminista atual refuta a ideologia que legitima a diferenciação de papéis, reivindicando a igualdade em todos os níveis, seja no mundo externo, seja no âmbito doméstico. Revela que esta ideologia encobre na realidade uma relação de poder entre os sexos, e que a diferenciação de papéis baseia-se mais em critérios sociais do que biológicos.

Desde a contribuição das autoras acerca do assunto, o feminismo se complexificou, podendo hoje se falar em feminismos, tendo em vista as diferentes vertentes (marxista, interseccional, radical e, até mesmo, liberal) e variados processos de mobilização. O ElasSobreOTatame se enquadra no feminismo interseccional, que algumas autoras destacam como sendo uma característica da quarta onda do feminismo, que é marcada ainda pela mobilização via meios de comunicação digitais, compreensão dessa diversidade de feminismos e mobilização em coletivos (PEREZ; RICOLDI, 2019). O projeto aqui analisado pode, portanto, também ser compreendido enquanto um ciberfeminismo (FELGUEIRAS, 2017), visto que a base de sua mobilização e realização se dá no ambiente virtual, ainda que, posteriormente, concretize-se em ações presenciais, conforme já detalhado anteriormente. 


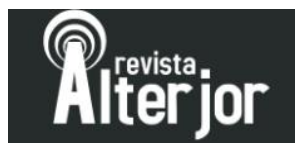

Ao amparar o seu midiativismo nesse ciberfeminismo interseccional, o ElasSobreOTatame pretende ampliar seu raio de ação, incluindo mulheres que vivenciam diferentes formas de exclusão e opressão. Entende-se que a interseccionalidade "traz consigo a ideia de superação de um feminismo branco e de classe média das ondas anteriores, conjugando elementos identitários como raça, gênero, classe, sexualidade, deficiência, etc” (PEREZ; RICOLDI, 2019, p. 11).

Ureta (2005) destaca que o midiativismo se constitui enquanto um espaço virtual e social que pode, cada vez mais, ser utilizado a serviço das mulheres, potencializando vivências de ativismos mais livres que aumentem as probabilidades de desenvolvimento de outros canais de comunicação e de trocas informativas, expandindo o contexto imediato das mulheres e suas comunidades, explorando cada dia mais as potencialidades expressivas do discurso utilizado na internet, por meio de seus recursos como a interatividade, a hipertextualidade e a multimedialidade.

\section{AVALIAÇÃO E APRENDIZADOS COM O PROJETO}

Objetivando compreender os impactos do projeto nas vivências das participantes foi realizada uma pesquisa de opinião, com perguntas objetivas e subjetivas, direcionadas à compreensão da emancipação, autonomia e formação de conhecimento acerca das temáticas abordadas nos eventos. Os resultados apreendidos, por meio desta pesquisa, visam incentivar a formação e desenvolvimento de iniciativas de combate ao silenciamento de informações, que são vitais para o fortalecimento da mulher, frente a uma sociedade desigual.

O questionário da pesquisa de opinião aplicada foi composto por nove questões objetivas que traziam como opções de respostas: discordo totalmente, discordo, indiferente, concordo e concordo totalmente. Antes de responder às perguntas, a participante deveria marcar o evento que havia participado, para que, com isso, não apenas o projeto como um todo pudesse ser avaliado, mas, também, os aspectos específicos dos encontros. Além disso, o questionário trazia, ainda, duas perguntas subjetivas, nas quais, as participantes poderiam dissertar livremente acerca da 


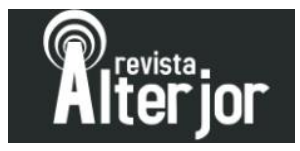

contribuição do evento no processo individual de emancipação, enquanto mulher, e sobre a possível ampliação de conhecimento com relação à temática abordada.

A pesquisa foi enviada, via Google Forms, para 65 participantes das três edições do projeto. Ao todo, 19 mulheres responderam ao questionário, o que representa $29,23 \%$ das pessoas consultadas. A maior parte das respostas $(63,2 \%)$ veio de participantes do terceiro encontro, o "Te cuida, mermã!", 36,8\% das respostas vieram de participantes da primeira edição, "Prazer Feminino e Autoconhecimento", e 21,1\% do segundo encontro, o "Maternidades".

Os retornos mais positivos foram acerca do ambiente e da escolha do tema dos eventos. O primeiro evento foi realizado no Laborarte, o segundo no auditório do Palacete Gentil Braga e o terceiro na Black Swan, um empreendimento de coworking ${ }^{9}$. Para a escolha dos ambientes, as organizadoras consideraram a comodidade, a privacidade e a facilidade de acesso, por meio de transporte público. Com relação ao acolhimento do ambiente proporcionado pelo evento, $89,5 \%$ concordaram totalmente com a afirmação de que o ambiente possibilitou segurança e conforto, em toda a sua duração, e 10,5\% apenas concordaram.

Foi registrada igual proporção e respostas para o questionamento se o tema do evento era considerado de fundamental importância para o empoderamento de mulheres. Ou seja, não houve qualquer retorno negativo ou indiferente com relação ao ambiente do Elas SobreOTatame e à escolha do tema abordado. Já com relação à abordagem da temática pelas profissionais convidadas, $84,2 \%$ concordam totalmente com a afirmação de que foi feita de maneira competente e 15,8\% apenas concordam.

Outro retorno muito positivo foi acerca dos momentos de diálogo entre as participantes do evento. 78,9\% concordaram totalmente com a afirmação de que eles foram muito enriquecedores e $21,1 \%$ apenas concordaram. Ao serem questionadas se a oportunidade de falar sobre assuntos íntimos com outras mulheres, durante o encontro, proporcionou bem-estar, $73,7 \%$ afirmaram que concordam totalmente e $26,3 \%$ que concordam. Ainda sobre os momentos de diálogo, 68,4\% concordaram totalmente que

\footnotetext{
${ }^{9}$ Espaço de compartilhamento de ambiente de trabalho. 


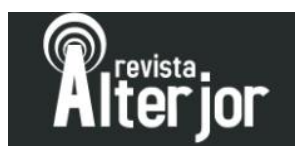

ouvir os relatos de outras mulheres, durante o encontro, as fortaleceu de algum modo, $26,3 \%$ apenas concordaram e 5,3\% optaram por serem indiferentes a essa afirmação.

A pesquisa sinalizou dois aspectos que podem ser melhorados. O primeiro é acerca do aprendizado sobre o tema. Das participantes que responderam à pesquisa, 47,4\% apontaram que concordam totalmente com a afirmação de que aprenderam algo novo sobre o tema durante a fala das profissionais, 36,8\% concordam e 15,8\% que discordam. Ou seja, algumas mulheres que estiveram presentes não conseguiram absorver um conhecimento novo acerca do assunto. Uma possível solução para este problema pode ser organizar os grupos de participantes em escalas de aprofundamento sobre a temática ou mesmo levar debates mais atuais ou menos generalistas sobre o tema trabalhado.

O segundo aspecto é sobre a criação de vínculos entre as participantes. 36,8\% concordam totalmente com a afirmação de que fez uma ou mais amizades com mulheres que conheceu no evento, $36,8 \%$ concordam, $15,8 \%$ discordam totalmente, $5,3 \%$ discordam e 5,3\% são indiferentes. A edição que apresentou mais respostas totalmente discordantes ou apenas discordantes foi a primeira, cujo foco era sexualidade. Ou seja, ainda há um espaço para trabalhar melhor o fortalecimento das conexões entre as participantes. Isso pode ser feito por meio de dinâmicas ou, talvez, ampliando a duração do evento, possibilitando, assim, mais tempo de convivência entre as mulheres.

As respostas ao questionamento de avaliação das atividades de encerramento dos eventos demonstram que há uma boa receptividade com relação às dinâmicas. 63,2\% das participantes concordaram totalmente com a afirmação de que a oficina (ou dinâmica) de encerramento trouxe uma vivência que potencializou o tema discutido e $36,8 \%$ apenas concordaram. Como se pode perceber, não foram registrados retornos negativos ou indiferentes com relação a este momento do evento. Recordando as oficinas de encerramento: no primeiro encontro, foi realizada uma oficina de exercícios pélvicos; no segundo, uma oficina de biodança; e na última edição, um momento de meditação guiada e mindfullness. Acredita-se que a recepção positiva quanto às dinâmica de encerramento se deva à escolha de atividades que buscaram momentos de integração, autocuidado e foco na saúde e bem-estar orientados por profissionais. 


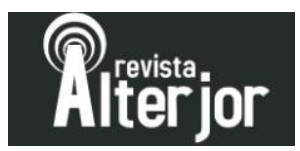

Conforme mencionado anteriormente, a pesquisa contou, ainda, com duas perguntas abertas, para que as participantes pudessem dissertar mais livremente sobre. A primeira das perguntas tinha por enunciado: "Você considera que a participação no evento contribuiu de algum modo com o seu processo individual de emancipação enquanto mulher?". Nesta, foi registrada apenas uma resposta negativa. A participante respondeu apenas "não", sem detalhar o porquê da não contribuição. As outras 18 respostas afirmaram que sim e, algumas, dissertaram a respeito dessa impressão individual positiva. Abaixo, estão as respostas mais detalhadas:

"Sim, sempre! ? Creio que o processo de emancipação é uma constante (des)construção. Tudo que vem pra somar é válido. Conversar e dividir sobre o universo feminino e suas peculiaridades com outras mulheres nos dá a chance de vermos que não estamos sozinhas. E que caminhar junto é bem melhor".

"Sim, foi muito interessante conversar com mulheres que passavam ou sentiam as mesmas coisas que eu em diversos momentos. Isso fez com que eu tivesse mais força no dia a dia para poder me posicionar sobre algumas questões nas quais eu achava que estava sozinha".

"Sim, nunca tinha me reunido com tantas mulheres para falar apenas sobre nós! Senti conexão com todas as participantes e uma sensação muito confortante de me conectar ainda mais comigo mesma. Eu saí muito fortalecida do evento! Grata".

As relações sociais de gênero se constituem de maneira desigual, os tabus que se estruturam em torno do feminino são profundamente enraizados no imáginario social, portanto, a proposta de rodas de conversas nos encontros presenciais do Elas SobreOTatame teve como objetivo principal fortalecer esse lugar coletivo de escuta e de fala, para que as narrativas que ali se produzissem, fossem pensadas como cadeias de significantes que gerariam impacto, desmistificações e transformação nas vivências subjetivas de cada participante. Pelas respostas obtidas, afere-se que tal objetivo foi alcançado pelos três eventos.

O compatilhamento de um conjunto de experiências, com mediação de profissionais, gerou um processo de identificação entre as mulheres e de ligação por causa das vivências tão similares, como bem exemplificado nas falas acima. Apesar do 


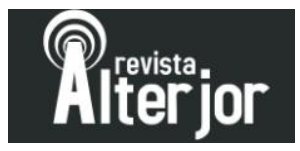

intuito das rodas não ter uma intencionalidade clínica, as três edições estruturaram intervenções que corroboraram para o processo de fortalecimento da emancipação das mulheres ali presentes, fosse discutindo prazer feminino, maternidades ou saúde mental. Afonso e Abade (2008) apontam que, quando os sujeitos conseguem compreender as maneiras pelas quais significam as experiências, entendem a sua forma de pensar e são capazes de discutir como chegaram a pensar daquela forma, há uma via para a reflexão, sendo possível assim articular novas signficações, dar novos sentidos e reivindicar novas posturas diante das vivências cotidianas. Pelas declarações coletadas na pesquisa, foi possível perceber que as rodas de conversa potencializaram esse processo nas participantes.

O questionário terminava com mais duas perguntas, complementares entre si: "Você diria que o evento ampliou seu conhecimento sobre a temática abordada? Por que?". O objetivo é que, aqui, as participantes pudessem detalhar as suas impressões acerca do processo pessoal de aprendizado com a experiência, pois, como define a Carta de São Bernardo, "o princípio da comunicação como direito humano fundamental pressupõe não somente o acesso, mas a construção de conteúdos, a apropriação da tecnologia e a multiplicação da diversidade cultural e da socialização do conhecimento (...)” (MARQUES DE MELO, 2006, p. 31). Portanto, essa pergunta teve como intenção saber se a comunicação estabelecida, por meio dos ciclos trabalhados, foi capaz de contribuir para esse processo de socialização do conhecimento. Dentre as respostas obtidas, estão:

"Sim, muito! Sobre sexualidade, apesar da mente muito aberta para a temática, a experiência de troca tão abertamente com outras mulheres foi muito nova! O processo de escuta foi muito enriquecedor. Adiciono também a oficina cheinha que coisas novas $\mathrm{e}$ surpreendentes. Com relação a saúde mental, aprendi o mais importante: eu não estou sozinha na luta"

"Sim. Os dois encontros que participei foram muito interessantes. Ampliou porque me apresentou profissionais da área da temática abordada muito competentes que souberam debater os assuntos com muita riqueza. Mais do que ampliar qualquer conteúdo específico, o importante é que instigou mudança de comportamento".

Revista ALTERJOR

Grupo de Estudos Alterjor:Jornalismo Popular e Alternativo (ECA-USP)

Ano 10 Volume Ol Edição 23 Janeiro-Junho de 2021

Avenida Professor Lúcio Martins Rodrig̉ues, 443, Cidade Universitária, São Paulo, CEP: 05508-020 


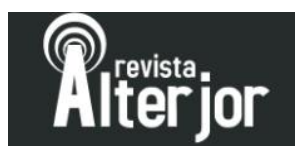

"Sim, principalmente ao escutar a Bartira falando. Percebi o quanto era importante discutir com outras pessoas essas questões e o quanto grupos de discussão fazem a diferença na construção de uma ideia. É superimportante se comunicar, principalmente com pessoas que estão dispostas a discutir sobre o assunto".

"Com certeza o evento ampliou minhas perspectivas sobre saúde mental. Pude perceber que interpretava autocuidado de maneira equivocada, além de entender como poderia fazer uma avaliação de pontos fortes e fracos e pontos de melhoria sobre mim mesma".

A presença de profissionais alinhadas com as temáticas trabalhadas nos ciclos permitiu um aprofundamento nas discussões, fortalecendo as propostas das rodas de conversa. A medida em que cada uma das mulheres discorria sobre as temáticas sugeridas, as convidadas faziam as marcações nas falas, potencializando os debates e criando cadeias de novos significantes. Vale ressaltar que o evento prezou pela troca de saberes e vivências. A presença das profissionais não tinha como intuito promover uma sobreposição de saberes, mas sim colaborar com a troca, como mais um dos muitos saberes disponíveis no mundo. Essas trocas eram feitas de maneira horizontalizada, criando um ambiente de diálogo entre todas.

Ávila (2009), recorrendo a teoria psicanálitica, vem destacar que o eu não existe sem o outro, é feito nas relações, é múltiplo, e somente na interação com o outro é possível constituir a subjetividade. Como demonstrado nas falas acima, a partir da troca, da mediação das profissionais e escuta de outras vivências, foi sendo possível uma socialização de saberes, uma reflexão sobre a posição de diferentes mulheres, atravessadas por diferentes vivências, marcadores sociais e histórias, acerca das temáticas propostas, conforme apregoa o feminismo interseccional. Constitui-se um processo intersubjetivo. Portanto, pode-se concluir que a metodologia utilizada nos encontros do Elas SobreOTatame foi efetiva por criar um ambiente de amplificação das vozes, uma vez que a escuta coletiva foi efetivada, tendo em vista os relatos coletados na pesquisa. Além disso, foi eficaz em criar um espaço acolhedor e seguro para essa troca de experiências.

Apenas duas respostas podem ser classificadas como discordantes, apesar das participantes frisarem que isso não desabonou a experiência do evento: 


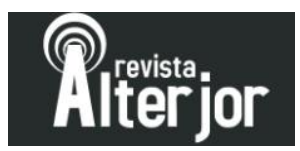

Não, na verdade discordei da fala da profissional em alguns aspectos, mas concordo que foi enriquecedor estar com outras mulheres comentando sobre saúde mental.

Acho que não porque já estava imersa na discussão dessa temática há um tempo. Mas isso não minimiza a experiência ótima que tive no evento. Ouvindo relatos, tive um estalo e repensei algumas coisas bem pessoais, então diria que ampliou conhecimentos sobre mim mesma.

Como mencionado anteriormente, espaços dialógicos horizontais implicam em apresentação de pontos de vista divergentes, por vezes. Sabe-se que a discordância é, também, um aspecto enriquecedor, visto que o desenvolvimento da civilidade se dá, sobretudo, pelo contato com o diferente (SENNET, 2007). Bauman (2001) destaca que a civilidade não pode ser praticada em outro ambiente que não o coletivo, o social. $\mathrm{O}$ conflito é, então, um aspecto fundamental no desenvolvimento e fortalecimento da cidadania, opondo-se a idealização de que precisa haver a concordância sobre todos os pontos discutidos.

A capacidade de conviver com a diferença, sem falar na capacidade de gostar dessa vida e beneficiar-se dela, não é fácil de adquirir e não se faz sozinha. Essa capacidade é uma arte que, como toda arte, requer estudo e exercício. A incapacidade de enfrentar a pluralidade de seres humanos e a ambivalência de todas as decisões classificatórias, ao contrário, se autoperpetuam e reforçam: quanto mais eficazes a tendência à homogeneidade e o esforço para eliminar a diferença, tanto mais difícil sentir-se à vontade em presença de estranhos, tanto mais ameaçadora a diferença e tanto mais intensa a ansiedade que ela gera (BAUMAN, 2001, p. 123).

Acredita-se, por fim, que essa experiência coletiva de roda de conversa se traduza por uma vivência política, constituída por múltiplos desejos de projetos comuns de transformação social, que ao criar uma atmosfera acolhedora, tolerante, democrática, desemborca na possibilidade de que cada participante possa contribuir com o processo individual em contar e recontar suas próprias realidades e histórias. 


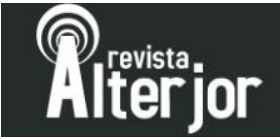

\section{CONSIDERAÇÕES E POSSIBILIDADES FUTURAS}

Diante do levante cada vez mais intenso do movimento feminista contra as diversas formas de silenciamentos, segregação, violências e aviltamento de direitos, fazse necessária uma atuação de mulheres nos mais amplos espaços de construção e propagação de discursos. É preciso abrir espaços mais frequentes para o diálogo, onde as mulheres, sobretudo, sintam-se capazes de se enunciarem enquanto sujeitas e pronunciarem o mundo a partir de modos específicos, particulares, locais de produção de sentido, pensando a si e a suas relações a partir da artesania própria de suas vivências, de seus corpos e de seus saberes.

Dentre esses ambientes que precisam ser cada vez mais ocupados está o online, que oportuniza formas próprias de comunicação e um alcance único, historicamente impossibilitados por meio dos veículos de comunicação tradicionais, seja pela exclusão de vozes periféricas ou pelas limitações técnicas desses veículos. De acordo com Tomazetti (2015), o crescimento do feminismo na internet e fora dela contribui para um reposicionamento do movimento politicamente, abrindo espaço para a ampliação de redes de compartilhamento de experiências, de saberes, de informações, contribuindo para a construção de vínculos solidários mais fortalecidos entre mulheres.

Portanto, ao gestar e alimentar um ciberativismo feminista que extrapola o ambiente on-line, o ElasSobreOTatame abriu um espaço de aglutinação de discursos de mulheres em busca de emancipação, de espaço propulsor de ideais, ações e potencialização de vida. Este artigo teve como objetivo mensurar de que modo o projeto impactou na vida das mulheres que participaram das três ações presenciais organizadas. E, com as respostas das participantes, ficou demarcada a importância desse ambiente de troca e escuta, bem como a presença de outras mulheres nessa trajetória comum na busca por transgressão do status quo socialmente imposto. O conteúdo que foi produzido on-line em cada ciclo e a interação virtual das redes encontram nas rodas de conversa uma espécie de catalisador de energias, que vivifica o ciberativismo por meio das presenças, das histórias comuns e incomuns que são compartilhadas. Este artigo, também, é o resultado desse trabalho de potencialização discursiva, pois se trata de uma 


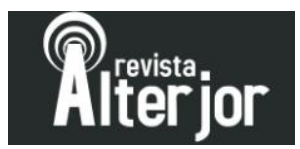

análise científica atravessada pelas próprias vivências de algumas das autoras, que trabalharam de forma direta com o projeto aqui avaliado.

A interatividade comunicacional promovida pelo projeto aumenta os espaços de ação do feminismo, a partir de um ciberativismo que recoloca os discursos numa perspectiva local, reutilizando os espaços culturais, políticos e tecnológicos para refazer redes discursivas, evidenciando vozes por vezes eclipsadas pelos veículos tradicionais de comunicação do Estado.

Cabe destacar que por meio da pesquisa, identificou-se, também, que o projeto deixa em aberto caminhos propositivos a serem trilhados a partir das críticas realizadas pelas participantes, cabendo para o futuro, pensar em novas abordagens ou formatos. Por fim, espera-se, com este artigo, propagar iniciativas como a do ElasSobreOTatame, que é um projeto que visa contribuir com a emancipação de mulheres e com o processo educativo para relações de gênero, para que o ciberativismo feminista ultrapasse fronteiras e reverbere entre grupos ainda mais diversos quanto às interseccionalidades de classe, gênero e raça.

\section{REFERÊNCIAS}

ALVES, Branca Moreira; PITANGUY, Jaqueline. O que é Feminismo. São Paulo: Brasiliense, Coleção Primeiros Passos, 1985.

ASSIS, I. P.; BETTI, Juliana Gobbi; SAMPAIO, Gustavo. Regionalidade, cultura e ativismo no jornalismo alternativo do SobreOTatame. In: Anais da XIV Conferência Brasileira de Comunicação Cidadã. Niterói: Universidade Federal Fluminense, 2019.

AFONSO, M. L.; ABADE, F. L. Para reinventar as rodas: rodas de conversa em direitos humanos. Belo Horizonte: RECIMAM, 2008.

ÁVILA, L. A. O eu é plural (Grupos: a perspectiva psicanalítica). In: Vínculo - revista do NESMe, v. 6, n. 1, jun, 2009.

BAUMAN, Z. Modernidade Líquida. Tradução Plínio Dentzien. Rio de Janeiro: Jorge Zahar, 2001.

ELIAS, Nobert; SCOTSON, John L. Os estabelecidos e os outsiders: Sociologia das relações de poder a partir de uma pequena comunidade. Rio de Janeiro: Zahar, 2000.

FELGUEIRAS, A. C. L. Breve Panorama Histórico do Movimento Feminista Brasileiro: das Sufragistas ao Ciberfeminismo. In: Revista Digital Simonsen, nº 6, p. 108-121, 2017.

\footnotetext{
Revista ALTERJOR

Grupo de Estudos Alterjor:Jornalismo Popular e Alternativo (ECA-USP)

Ano 10 Volume ol Edição $23 \quad$ Janeiro-Junho de 2021

Avenida Professor Lúcio Martins Rodriģues, 443, Cidade Universitária, São Paulo, CEP: 05508-020
} 


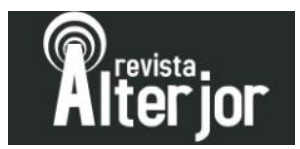

FERREIRA, Giovandro Marcus. Da comunicação/educação que temos à Comunicação/educação que queremos: um mundo em busca de muitas vozes. In: BARBOSA, M, Fernandes, M.; MORAIS, O. J. de (Orgs.). Comunicação, educação e cultura na era digital. São Paulo: Intercom, 2009.

FIGUÊREDO, A. A. F; QUEIROZ, Tacina Nogueira de. A utilização de rodas de conversa como metodologia que possibilita o diálogo. In: Anais do Seminário Internacional Fazendo Gênero 10 (Anais Eletrônicos), Florianópolis, 2012. ISSN 2179-510X.

FREIRE, Paulo. Pedagogia da Autonomia. São Paulo: Paz e Terra, 2011.

LIMA, Venício A. de. As concessões de radiodifusão como moeda de barganha política. In: Revista Adusp, $n^{\circ}$ 42, janeiro, 2008.

MARQUES DE MELO, José. Mídia e Cidadania no Brasil. In: MARQUES DE MELO, J.; GOBBI, M.C.; SATHLER, L. (Orgs.). Mídia Cidadã: utopia brasileira. São Bernardo do Campo: Universidade Metodista de São Paulo, 2006.

MARTÍN-BARBERO, Jesus. Ofício de cartógrafo. Travessias latino-americanas da comunicação na cultura. São Paulo: Edições Loyola, 2004.

PASQUALI, Antonio. Um breve glossário descritivo sobre comunicação e informação (para clarear e melhorar o entendimento mútuo). In: MARQUES DE MELO, J.; SATHLER, L. (Orgs.). Direitos à comunicação na Sociedade da Informação. São Bernardo do Campo: Universidade Metodista de São Paulo, 2005.

PEREZ, Olívia Cristina; RICOLDI, Arlene Martinez. A Quarta Onda Feminista: interseccional, digital e coletiva. In: Anais do $\mathbf{X}$ Congresso Latino-americano de Ciência Política (ALACIP), Monterrey, 2019. Disponível em: https://alacip.org/cong19/25-perez-19.pdf. Acesso no dia 17 de outubro de 2020.

PERUZZO, Cicilia. Cidadania comunicacional e tecnopolítica: feições do midiativismo no âmbito dos movimentos sociais populares. In: BRAIGHI, A. A., Lessa, C.; CÂMARA, M. T. (Orgs.). Interfaces do Midiativismo: do conceito à prática. CEFET-MG: Belo Horizonte, pp. 43-61, 2018.

PINTO, Pâmela. Mídia e Política no Brasil: Grande Imprensa x Coronelismo Eletrônico. In: Anais do Congresso Brasileiro de Ciências da Comunicação - Intercom, 32, Curitiba, São Paulo: Intercom, pp. 1-15, 2009.

SANTOS, Milton. O Espaço do Cidadão. São Paulo: Edusp, 2014.

SENNETT, R. Una ciudad flexible de extraños. ARQ, (66). pp. 19-23, 2007. Disponível em: https://repositorio.uc.cl/bitstream/handle/11534/9009/000480855.pdf?sequence=1\&isAllowed =y. Acesso em 14 de fevereiro de 2018.

TOMAZETTI, Tainan Pauli. O feminismo na era digital e a (re)configuração de um contexto comunicativo para políticas de gênero. In: Revista Razón y Palabra, Quito, v. 19, n. 90, pp. 489-500, jun./ago, 2015. Disponível em: https://revistas.ucm.es/index.php/ESMP/article/view/ESMP0505110375A/12513. Acesso em 22 de outubro de 2020.

URETA, Ainara Larrondo. La Red al servicio de las mujeres. In: Aproximación a la relación mujer y medios de comunicación en Internet. Estudios sobre el Mensaje Periodístico, Madrid, v. 11, n. 11, pp. 375-392, 2005. Disponível em:

Revista AL TERJOR

Grupo de Estudos Alterjor:Jornalismo Popular e Alternativo (ECA-USP)

Ano 10 Volume Ol Edição 23 Janeiro-Junho de 2021

Avenida Professor Lúcio Martins Rodriġues, 443, Cidade Universitária, São Paulo, CEP: 05508-020 


\section{Areiorior}

https://revistas.ucm.es/index.php/ESMP/article/view/ESMP0505110375A/12513. Acesso em 21 de outubro de 2020. 